\title{
Sexual Desire in the Time of COVID-19: How COVID-Related Stressors are Associated with Sexual Desire in Romantic Relationships
}

\author{
Rhonda N. Balzarini ${ }^{1,4}$, Amy Muise ${ }^{2}$, Giulia Zoppolat ${ }^{3}$, Amanda N. Gesselman ${ }^{4}$, Justin J. \\ Lehmiller $^{4}$, Justin R. Garcia ${ }^{4,5}$, Richard B. Slatcher ${ }^{6}$, and Kristen P. Mark ${ }^{4,7}$. \\ ${ }^{1}$ Department of Psychology, Texas State University, San Marcos, TX, United States \\ ${ }^{2}$ Department of Psychology, York University, Toronto, ON, Canada \\ ${ }^{3}$ Department of Experimental and Applied Psychology, Vrije University, Amsterdam, \\ Netherlands \\ ${ }^{4}$ The Kinsey Institute, Indiana University, Bloomington, IN, United States \\ ${ }^{5}$ Department of Gender Studies, Indiana University, Bloomington, IN, United States \\ ${ }^{6}$ Department of Psychology, University of Georgia, Athens, GA, United States \\ ${ }^{7}$ Department of Family Medicine \& Community Health, University of Minnesota Medical \\ School, Minneapolis, MN, United States
}

Correspondence concerning this article should be addressed to Rhonda Balzarini, Department of Psychology Main Office, Texas State University, San Marcos, TX 78666. E-mail: rbalzarini@txstate.edu. 


\begin{abstract}
The COVID-19 pandemic and the resulting social distancing measures have caused widespread social and economic disruptions, resulting in spikes in unemployment and financial instability, along with drastic changes to people's ability to feel socially connected. Many of the changes resulting from the COVID-19 pandemic are risk factors for depressive symptoms, which are associated with lower levels of sexual desire. The current research $(N=4,993)$ examined whether responses to external stressors brought on by COVID-19 (i.e., financial concern, worry, loneliness, stress) were associated with sexual desire among a multi-national sample of people in relationships (Studies 1-2), and whether this association was, in part, due to reports of depressive symptoms (Study 2). In the period immediately following the onset of the pandemic, more financial concern (Study 1) and worry (Study 2) were associated with higher sexual desire, while other factors, like stress (Studies 1-2), were associated with lower desire. We also followed a subset of participants every two weeks during the initial stages of the pandemic and at times when people reported greater stress, loneliness, financial strain, or worry than their average, they reported greater depressive symptoms, which, was in turn, associated with lower sexual desire. Results suggest that the social isolation and stress resulting from the COVID-19 pandemic has mixed associations with sexual desire at the onset of the pandemic. But over time, when people report heightened COVID-related stressors, they tend to report lower sexual desire for their partner, in part because these stressors are associated with more depressive symptoms. Keywords: COVID-19; Financial Strain; Loneliness; Stress, Sexual Desire; Romantic Relationships
\end{abstract}




\section{Sexual Desire in the Time of COVID-19: How COVID-Related Stressors are Associated with Sexual Desire in Romantic Relationships}

On March $11^{\text {th }}, 2020$, COVID-19 was declared a global pandemic and stay at home orders were mandated throughout the world. The measures implemented to reduce the spread of COVID-19 led to financial instability (Congressional Research Service, 2020; Gangopadhyaya \& Garrett, 2020; King, 2020) and drastic changes to people's ability to socially connect and participate in daily activities (Brooks et al., 2020). Although research has begun to explore the impact of COVID-19 on general psychological well-being, less is known about changes to people's sex lives amidst the COVID-19 pandemic. When the pandemic first began, and much of the world went into lockdown, some speculated that couples isolated together might experience higher sexual desire and engage in more frequent sex given their increased time together, producing a year-end baby boom (e.g., Bakar, 2020; Fordham, 2020; Whittle, 2020). The betting odds site SportsBettingDime.com went so far as to release odds of a Trojan condom stock boom amid the pandemic (Coyle, 2020), and indeed, initial reports at the onset of the pandemic indicated that condom sales increased in the United States, as did sales for sex toys (Mellor, 2020), and the use of pornography (Li et al., 2020; Mestre-Bach et al., 2020; Pornhub Insights, 2020). But, more than a year after the onset of the pandemic there is mounting evidence that the pandemic is instead taking a toll on people's sex lives. For example, research from several countries has shown that people are reporting changes in sexual habits and lower levels of sexual desire (Li et al., 2020; Lehmiller et al., 2020; Yuksel \& Ozgor, 2020), as well as poorer sexual functioning (Döring, 2020), lower sexual satisfaction (Cocci et al., 2020; Mark et al., 2020), and less frequent sex (Cito et al., 2020; Lopes et al., 2020) compared to pre-pandemic reports. One reason people might be experiencing declines in their sexual desire and sexual functioning is that 
couples are currently experiencing a host of negative emotional reactions - such as loneliness, stress, financial strain, and worry - in response to the multitude of external stressors introduced during COVID-19, which have been associated with more depressive symptoms (e.g., Hammen, 2005; Holt-Lunstad et al., 2010; Slavich \& Irwin, 2014; Zimmerman \& Katon, 2005) and could ultimately be associated with lower levels of sexual desire. In the current research, we investigate how people's reactions to COVID-related stressors are associated with reports of sexual desire for a romantic partner.

\section{COVID-Related Stressors and Sexual Desire}

The COVID-19 pandemic introduced a host of external stressors that have led to increased loneliness, stress, financial strain, and worry about COVID-19, and spilled over into people's relationships and interest in sex. More specifically, stay-at-home orders, which were mandated throughout the world to mitigate the spread of COVID-19 (Koo, Cook, \& Park, 2020; Lewnard \& Lo, 2020), involved drastic changes to people's daily activities, and resulted in many people social distancing together with their romantic partner for an extended period of time, often both working and caring for children from home (Carlson, Petts, \& Pepin, 2020), having to balance work, household responsibilities and childcare (Gordon, Cross, Ascigil, Balzarini, Luerssen, \& Muise, 2022). The COVID-19 pandemic also had economic consequences with spikes in the unemployment rate worldwide leading to levels of unemployment that were higher than the Great Recession and Great Depression (Faria e Castro, 2020; Kochhar, 2020; Pappas, 2020). Past research suggests that these types of chronic external stressors put couples at risk for relationship dissatisfaction (e.g., Bolger, DeLongis, Kessler, \& Wethington, 1989; Buck \& Neff, 2012; Neff \& Karney, 2004; Randall \& Bodenmann, 2009) and have been shown to lead to more 
conflict and dissatisfaction among couples during the COVID-19 pandemic (Balzarini et al., 2022).

Although little is known about how people's reactions to external stressors effect sexual desire, accumulating evidence suggests that people confronted with stressful life events often experience negative sexual intimacy consequences (Bodenmann, Ledermann, et al., 2006; Hagemeister \& Rosenblatt, 1997; Morokoff \& Gillilland, 1993), including lower sexual desire and satisfaction (Leavitt \& Willoughby, 2015; Montesi, Conner, Gordon, Fauber, Kim, \& Heimberg, 2013; Rokach, 2019) and higher reports of sexual dysfunction (see Bodenmann, Ledermann, Blattner-Bolliger, \& Galluzzo, 2006). Indeed, loneliness has been found to be associated with greater self-centeredness (Cacioppo, Chen, \& Cacioppo, 2017), less selfdisclosure in social interactions (Wei et al., 2005), a tendency to physically withdraw from social interactions (Qualter et al., 2015), a preference for greater interpersonal distance (Layden et al., 2018), and lower sexual frequency and less affectionate touch (Mund et al., 2020). Similarly, financial strain and stress affiliated with losing a job can erode a person's sense of competence and well-being (Ervasti \& Venetoklis, 2010) and has been shown to be associated with poorer relationship quality (Bodenmann, 1997; Conger et al., 1999; Karney et al., 2005), increased conflict and hostility toward one's partners (for a review see Story \& Bradbury, 2004), as well as lower sexual desire and higher sexual dysfunction when people experience greater stress from unemployment, (e.g., among men, Beutel, Stöbel-Richter, \& Brähler, 2008; Laumann, Paik, \& Rosen, 1999; Martin, Atlantis, Lange, Taylor, O’Loughlin, \& Wittert, 2014; and among women, Çayan, Akbay, Bozlu, Canpolat, Acar, \& Ulusoy, 2004).

Research examining the associations between sexual function and measures of stress have presented mixed results. For example, in several studies, heightened stress has been shown 
to be associated with higher sexual function (e.g., Hamilton \& Julian, 2014), more frequent sexual intercourse (e.g., Bodenmann et al., 2007; Hall, Kusunoki, Gatny, \& Barber, 2014) and higher sexual desire (Morokoff \& Gillilland, 1993), in other cases, heightened stress has adverse effects on sexuality (e.g., Bodenmann, Atkins, Schar, \& Poffet, 2010), especially for women (Hamilton \& Metson, 2013). The Dual Control Model (Bancroft \& Janssen, 2000; Bancroft, Graham, Janssen, \& Sanders, 2009), proposes that the strength of a sexual response depends on a person's propensities for excitation (i.e., arousal response and motivation toward sex) and inhibition (i.e., decreased arousal response and turning away from sex). This model highlights the idea that an accumulation of stressors can inhibit an individual's sexual responses, dampening their sexual arousal. That is, according to the Dual-Control Model (Bancroft \& Janssen, 2000; Bancroft et al., 2009), stress would not interfere with people's sexual arousal universally, rather this model would postulate that people who are more sensitive to stressors as sexual inhibitors would be impacted. Although the model focuses on sexual arousal, this often overlaps with sexual desire (e.g., Basson, 2001; 2008; Mitchell et al., 2014). Indeed, some initial support for the application of this model in response to the pandemic comes from a recent study finding that worry, a lack of privacy, and stress were among the top reasons for the changes in sexual behavior (Panzeri, Ferrucci, Cozza, \& Fontanesi, 2020). As such, we expected that people's emotional reactions to external stressors- such as heightened reports of loneliness, general levels of stress, financial strain, and worry - that have been brought on by COVID-19, would be negatively linked to people's reports of sexual desire for their partner.

\section{The Role of Depressive Symptoms}

Although past research has not assessed sexual desire in the wake of a prolonged period of both forced cohabitation and social distancing, past research does find that people who 
experience chronic stress, such as challenging social, relational, or financial conditions, are at risk for depression and psychological distress (e.g., Hammen, 2005; Holt-Lunstad et al., 2010; Slavich \& Irwin, 2014; Zimmerman \& Katon, 2005), factors that are often associated with lower levels of sexual desire, as well as less sexual arousal, pleasure, and satisfaction (e.g., Kalmbach, Ciesla, Janata, \& Kingsberg, 2015). Negative life events (e.g., exposure to a hurricane, death of a child) are significantly associated with mental health challenges, such as depression and anxiety (Kopala-Sibley et al., 2016; Spinhoven et al., 2011). In fact, research suggests that depressive symptoms have risen in response to COVID-19, with a recent meta-analysis showing that rates of depressive symptoms were seven times higher since the onset of the pandemic (BuenoNotivol et al., 2021). Specific to COVID-19, uncertainties about work and health, along with social distancing during periods of forced lockdown have had an impact on psychological adjustment, influencing people's reports of anxiety and depression, disturbing sleep and eating patterns, and inducing somatic symptomatology (Ahmed, Ahmed, Zhou, Sang, Liu, \& Ahmad, 2020; Cellini, Canale, Mioni, \& Costa, 2020; Fernández-Aranda et al., 2020; Huang \& Zhao, 2020; Tian, Li, Tian, Yang, Shao, \& Tian, 2020; Zhang et al., 2020). Past research has demonstrated that there is a consistent link between loneliness and depression (Hakulinen et al., 2018; Holt-Lunstad, Smith, Baker, Harris, \& Stephenson, 2015) and has shown that loneliness predicted depression over time, regardless of initial depression levels (Cacioppo, Hawkley, \& Thisted, 2010; Cacioppo, Hughes, Waite, Hawkley, \& Thisted, 2006). The mounting evidence suggests that people's emotional reactions to stressors that have been introduced during COVID19 are risk factors for depressive symptoms, which might then have consequences for people's relationships and sex lives. 
Experiencing depressive symptoms can have a variety of negative effects on sexual functioning. For example, a high percentage of people suffering from mild to severe forms of depression report experiencing sexual dysfunction (see Hartmann, 2007) and past research has found consistent links between psychological symptoms and sexual desire problems (Aksaray, Yelken, Kaptanoglu, Oflu, \& Özaltin, 2001; Dobkin, Leiblum, Rosen, Menza, \& Marin, 2006; Hartmann, 2007; Michael \& O’Keane, 2007; Minnen \& Kampman, 2000; Segraves, 2002). Given the previous research showing that people who experience high levels of stress experience heightened levels of depression, and that depressive symptoms are linked to lower levels of desire and sexual functioning, we explored whether the association between COVID-related stressors and sexual desire were mediated by people's reports of depressive symptoms. That is, we expected people who reported more COVID-related stressors to report greater depressive symptoms, and that greater depressive symptoms would, in turn, negatively impact people's sexual desire.

\section{The Current Study}

In the current research, we investigate whether people's reactions to COVID-related stressors - like general levels of loneliness, stress, financial strain, and worry about COVID19 - are associated with reports of sexual desire for a romantic partner at the onset of the pandemic and over time. Examining these associations during a global pandemic provides a unique opportunity to understand the effect of emotional reactions to external stressors on sexual desire among couples, even those who normally might not be exposed to high levels of stress. Given the accumulating evidence that loneliness, stress, financial strain, and worry are risk factors for depression and psychological distress (e.g., Holt-Lunstad et al., 2010; Zimmerman \& Katon, 2005), which are often associated with lower levels of sexual desire (e.g., Kalmbach et 
al., 2015), we predicted that people who experienced more negative emotional reactions to COVID-related stressors would report lower sexual desire (assessed in Studies 1-2), but, that the association between COVID-related stressors and sexual desire would be accounted for by people's reports of depressive symptoms (assessed in Study 2 only). Specifically, we expected that people who experienced more negative emotional reactions to COVID-related stressors would experience more depression, and, in turn, report lower sexual desire. The hypotheses for these studies were pre-registered on the Open Science Framework (OSF).

\section{Study 1}

\section{Method}

\section{Participants and Procedure}

Participants were drawn from the Sex and Relationships in the Time of COVID-19 Study, which launched on March $21^{\text {st }}$. Baseline data from participants were collected at the beginning of the COVID-19 pandemic. The survey was available in English and participants were asked to complete follow-up surveys every two weeks for a total of six weeks (Wave 1-Wave 3).

Participants were recruited using an internet-based snowball sampling method, with initial standardized messages posted to the Kinsey Institute's public social media platforms (Facebook, Twitter, Instagram, LinkedIn). Recruitment posts were then widely shared and reposted by other social media users (e.g., individuals, organizations, researchers) including by those participating, resulting in a demographically diverse and multi-national participant pool, albeit not representative of any particular nation (74\% of participants were from the US, $26 \%$ were from other countries outside of the US, mostly Canada and Europe). To be eligible, participants had to be at least 18 years of age. A pre-registered power analysis indicated that 934 participants would be needed to estimate a small main effect $(f=.02)$ with four predictors and with $95 \%$ power at 
one time point (power estimated using G-Power 3.1; Erdfelder, Faul, \& Buchner, 1996; Faul, Erdfelder, Buchner, \& Lang, 2009). A total of 4,452 individuals accessed and consented to participate in the online study, of those, 3,083 were removed because they were not in a relationship. More specifically, given that our research questions are focused on sexual desire among people in romantic relationships, we analyzed data from the subset of participants who reported currently being in a romantic relationship during the study. The current sample initially (i.e., at Wave 1) consisted of 1,369 individuals in relationships. Participants were primarily heterosexual (59.4\%), and the majority were women (69.6\%). Participants were in their mid-30's on average $(M=36.10$ years old, $S D=10.99)$, mostly in long-term $(M=9.22$ years, $S D=8.77)$ relationships (52.5\% married), and were living at the same place and engaging in social isolation together (83.0\%; see Table 1 for more demographic details).

Eligible participants completed an online survey (launched March 21, 2020 and closed on April 14, 2020) shortly after a global pandemic was declared (March 11, 2020) and much of the world had issued stay-at-home or shelter-in-place orders. The survey asked participants about their experience since the onset of the COVID-19 pandemic including their social isolation, stress, financial concern, worry, and sexual desire. Additional measures were included for other purposes (see other publications from this research; BLIND FOR REVIEW). All participants were eligible to enter a raffle to receive an electronic gift card each wave ranging from $\$ 10-50$ USD and increasing in amount with each wave completed. More specifically, in Wave 1 participants were eligible to receive one of $100 \$ 10.00$ electronic gift cards for participating, whereas for Wave 2, participants were eligible to enter a raffle for a \$20 electronic gift card, and Wave 3 was a $\$ 50$ gift card. The study procedures were approved by the IRBs of the host institutions prior to beginning research. 


\section{Measures}

We assessed the constructs of interest using truncated versions of the focal measures or the most representative single item from well-validated scales to keep the survey as brief as possible in order to reduce fatigue, increase efficiency, and minimize participant attrition (Bolger, Davis, \& Rafaeli, 2003). All measures were assessed at background (Wave 1) and in subsequent follow-up surveys (see Table 2 for the means of all the focal variables across the time points).

Loneliness. The revised UCLA Loneliness Scale (Hughes, Waite, Hawkley, \& Cacioppo, 2004) was used to assess loneliness, the subjective experience of social isolation (three items; e.g., "How often do you feel: 'that you lack companionship' 'left out' and 'isolated from others"'). Possible responses were on a 3 -point scale $(1=$ hardly ever, $2=$ some of the time, $3=$ often), and the items were mean aggregated, with higher scores indicating more loneliness at Wave $1(\alpha=.77 ; M=1.64, S D=0.53)$ and over time $(M=2.15, S D=0.83)$.

General Stress. A Global Measure of Perceived Stress (Cohen, Kamarck, \& Mermelstein, 1983) was used to assess stress (two items; e.g., "In the last 2 weeks, how often have you felt that you were unable to control the important things in your life?"; "In the last 2 weeks, how often have you felt difficulties were piling up so high that you could not overcome them?"). Possible responses were on a 5 -point scale $(1=$ never, $5=$ very often $)$, and the items were mean aggregated, with higher scores indicating greater stress at Wave $1(\alpha=.75 ; M=2.82$, $S D=0.71)$ and over time $(M=4.27, S D=1.87)$.

Financial Concern. A single item was used to assess worry about the financial impact of the COVID-19 pandemic (e.g., "To what extent do you worry about the financial impact the current COVID-19 pandemic will have on you personally?"). Possible responses were on a 7- 
point scale $(1=$ not at all, $7=$ very $m u c h)$, with higher scores on this item indicating greater worry about the financial impact of COVID-19 at Wave $1(M=4.35, S D=1.77)$ and over time $(M=4.34, S D=1.85)$.

COVID-Related Worry. Six items were used to assess worry about COVID risk for oneself and others. Participants were asked to indicate the extent to which they were worried for the health and safety of the following persons during the pandemic: "self," "close family," "close friends," partner(s)," "my local community," and "society at large." Possible responses were on a 7-point scale ( 1 = low worry, 7 = higher worry), and the items were mean aggregated, with higher scores indicating more worry at Wave $1(\alpha=.83 ; M=4.83, S D=1.18)$ and over time $(M$ $=4.70, S D=1.23$ ).

Sexual Desire for Partner. One item was used to assess individuals sexual desire for their partner (e.g., "Over the past 2 weeks, how often did you feel sexual desire or interest for your partner?”; adapted from Impett, Strachman, Finkel, \& Gable, 2008). Possible responses were on a 5-point scale $(1=$ almost always or always, $5=$ almost never or never $)$. The response was reverse coded, with higher scores indicating greater desire for one's partner at Wave $1(M=$ 3.49, $S D=1.23)$ and over time $(M=3.44, S D=1.21){ }^{1}$

\section{Results}

\section{Reactions to COVID-Related Stressors and Sexual Desire at the Onset of the Pandemic}

\footnotetext{
${ }^{1}$ An additional measure examining dyadic sexual desire (e.g., desire to engage in sexual activity with a partner generally) was also included in Study 1 and the results for this measure are reported in the Supplemental Materials. The associations were replicated with this other measure (and an additional association between loneliness and worry was significant with this measure). We choose to report this measure in text since it was the most direct assessment of desire for a romantic partner.
} 
The data and syntax for all analyses reported for this paper can be found on the OSF. Means for each of the focal measures across the waves are presented in Table 2, and correlations between all variables are presented in Table 3.

Using multiple regression, we found that when people reported more stress at onset of the pandemic, they reported feeling lower sexual desire for their partner. But, contrary to our predictions, when people reported more concern about the financial impact of COVID-19, they reported more sexual desire for their partner, while reports of worry about themselves or others contracting COVID, and reports of loneliness, were not associated with people's reports of sexual desire for their partner (see Table 4 for more details).

\section{Reactions to COVID-related Stressors and Sexual Desire Overtime}

As stressors can change over the course of the pandemic, in the next set of analyses we look at within-person changes in COVID-related stressors and sexual desire to see if, at times when people report more stressors than typical, they report lower sexual desire. To test these longitudinal effects, we ran a series of multilevel models with each timepoint (three total) nested within-person and estimated random intercepts and slopes - an approach that allow us to disentangle the within and between-person differences and thus we can estimate the withinperson fluctuations from wave to wave while ensuring that the effects are not driven by the between person variances (see Zhang, Zyphur, \& Preacher, 2009). Predictors were person-mean centered and aggregated, but we focus on the person-mean centered (within-person) effects to test whether changes in COVID-related stressors were associated with changes in sexual desire in the initial months of the pandemic. Results suggest that when people reported more loneliness than their own average, they reported lower sexual desire for their partner. However, no effects 
emerged for people's reports of stress, financial concern, or worry about COVID and their sexual desire for their partner (see Table 4).

\section{Providing Evidence for Generalizability of the Findings}

Next, given the wide-ranging literature on gender differences in sexuality in relationships (see review by Peplau, 2003), and because sexual desire has been shown to generally decrease with age (Beutel, Stöbel-Richter, \& Brähler, 2008; Kontula \& Haavio-Mannila, 2009), across the studies, we conducted exploratory analyses to test whether men versus women were more impacted by COVID-related stressors, and whether age influenced the impact of COVID-related stressors on people's reports of sexual desire. In Study 1, gender did not significantly moderate the effects for loneliness, stress, financial strain, or worry about COVID-19 on people's reports of sexual desire at the onset of the pandemic. Similarly, age did not significantly moderate the effects for loneliness, stress, financial strain, or worry about COVID-19 on people's reports of sexual desire at the onset of the pandemic or over time. These results suggest that in this study the associations between COVID-related stressors on reports of people's sexual desire for one's partner are consistent for both men and women across diverse age ranges at the onset of the pandemic and over time (see the Supplemental Materials for more information).

\section{Study 2}

In Study 2, we sought to replicate and extend the findings from Study 1 using a large, international sample and examining the effects over a longer period of time. Importantly, Study 2 is a separate study that involved a new set of participants who were recruited by a different research team. Consistent with Study 1, we expected that when people reported greater COVIDrelated stressors at the onset of the pandemic and over time (compared to their own average across the study), they would report lower sexual desire for their partner. Yet, we also sought to 
test a possible mechanism for the associations between COVID-related stressors on people's reports of sexual desire for their partner. That is, past research has shown that external stressors like those that have been introduced during the COVID pandemic can cause a host of negative emotional reactions (e.g., stress, loneliness, financial strain, and worry) that are associated with depressive symptoms, and other research has shown that depressive symptoms are associated with lower levels of desire (Kalmbach et al., 2015). As such, in Study 2 we also tested whether COVID-related stressors were associated with depressive symptoms, and in turn, associated with lower reports of people's sexual desire for their partner. As in Study 1, we also explored whether a person's self-identified gender or age influenced the effects.

\section{Method}

\section{Participants and Procedure}

Participants were drawn from the Love in the Time of COVID Study — an ongoing longitudinal project examining the effects of the COVID-19 pandemic on how people connect, relate, and cope during the COVID-19 pandemic. Data collection for Wave 1 (T1) began on March 27, 2020. The survey was initially available in English and was translated to 10 different languages (Spanish, Turkish, Thai, Chinese, Dutch, French, German, Indonesian, Italian, and Portuguese) using back-translation procedures to ensure there were no discrepancies across the different versions of the survey (see Colina, Marrone, Ingram, \& Sanchez, 2017; Tyupa, 2011). Participants were recruited online from social media sites (e.g., Facebook, Instagram, Reddit) and through the study website (BLIND FOR REVIEW). Like the recruitment for Study 1, initial recruitment posts were then shared widely resulting in a demographically diverse and multinational participant pool. To be eligible, participants had to be at least 18 years of age and pass one of two attention checks embedded in the survey. Participants who completed the baseline 
survey were asked to complete follow-up surveys every two weeks for a total of three months (T1-T6). A pre-registered power analysis (Erdfelder et al., 1996; Faul et al., 2009) indicated that 934 participants would be needed to estimate a small main effect $(f=.02)$ with $95 \%$ power. Over 7000 individuals from across the world accessed the online study, of those, 2,058 were removed because they failed at least one of the two attention checks, were removed for indicating they did not pay attention to the questionnaire or did not complete enough surveys (participants who completed three or more of the surveys were included). ${ }^{2}$ This resulted in 5,638 participants. As in Study 1, in Study 2 we analyzed data from the subset of participants who reported currently being in a romantic relationship. The current sample consisted of 3,624 individuals in relationships. Participants were from 57 countries (additional country-level detail can be found in the Supplemental Materials), were mainly heterosexual (83.6\%), and the majority were women (78.1\%). Participants were in their early 30's on average $(M=32.97$ years old, $S D=12.57)$ and mostly in long-term $(M=8.30$ years, $S D=9.99)$ intimate relationships $(57.5 \%$ dating $)$ and were living at the same place and engaging in social isolation together $(83.2 \%$; see Table 1 for more demographic details).

Eligible participants completed an online survey (launched March 27, 2020, and closed on May 8,2020). The survey asked participants about their experience since the onset of the COVID-19 pandemic including their loneliness, stress, financial strain, worry, sexual desire, and depression. Additional measures were included for other purposes and can be found on the OSF. Participation in this study was entirely voluntary (i.e., no compensation was provided for

\footnotetext{
${ }^{2}$ As commonly employed in the literature (e.g., Berinsky, Margolis, \& Sances, 2014; Curran, 2016), Study 2 included pre-registered attention check questions, wherein we asked participants to select a particular answer choice for that question (e.g., "Please select "Agree a little." This is not a trick question."). Additionally, participants were asked to indicate how much attention they paid while completing the questionnaire. Possible responses were on a 4point scale $(1=$ no attention, $2=$ very little attention, $3=$ moderate amount of attention, $4=$ very close attention $)$, and participants who indicated they paid very little or no attention to the questionnaire (response of 2 or lower) will be excluded.
} 
participation), and the study procedures were approved by the IRB's host institutions prior to beginning research.

\section{Measures}

We assessed the constructs of interest using truncated versions of the focal measures or the most representative single item from well-validated scales to keep the survey as brief as possible to reduce fatigue, increase efficiency, and minimize participant attrition (Bolger et al., 2003). All measures were assessed at background (Wave 1) and in subsequent follow-up surveys (see Table 2 for the means of all focal variables across the time points).

Loneliness. Two items from the UCLA Loneliness Scale (Hughes et al., 2004) were used to assess subjective loneliness, the subjective experience of social isolation (e.g., "In the last two weeks, I felt: 'lonely' and 'isolated"”). ${ }^{3}$ Possible responses were on a 5-point scale $(1=$ very slightly/not at all, $5=$ extremely), and the items were mean aggregated, with higher scores indicating more loneliness at Wave $1(r(3620)=.62, p<.001 ; M=2.43, S D=1.21)$ and over time $(M=2.22, S D=1.15)$.

General Stress. Two items were used to assess stress (e.g., "In the last two weeks, I felt: 'stressed' and 'distressed'”; adapted from Watson \& Clark, 1999). Possible responses were on a 5-point scale ( 1 = very slightly/not at all, $5=$ extremely $)$, and the items were mean aggregated, with higher scores indicating more stress at Wave $1(r(3616)=.62, p<.001 ; M=2.97, S D=$ 1.11) and over time $(M=2.86, S D=1.08)$.

Financial Strain. A single item was used to assess financial strain. This item was originally derived from Pearlin and colleagues (1981) and revised by Okechukwu and colleagues (2012). In the current study, we revised this measure to specifically ask about

\footnotetext{
${ }^{3}$ Note that the effects are the same with the items assessed individually.
} 
financial strain cause by COVID-19 (e.g., "To what degree has the recent COVID-19 outbreak negatively impacted your financial situation?"). Possible responses were on a 5-point scale $(1=$ not at all, $5=$ extremely), with higher scores on this item indicating greater perceived financial strain over COVID-19 at Wave $1(M=2.39, S D=1.11)$ and over time $(M=2.19, S D=1.14)$.

COVID-Related Worry. Two items were used to assess worry about COVID risk for the self and others (e.g., “To what degree are you ‘worried about getting or having COVID-19?', 'worried about family members or friends getting COVID-19?'"). Possible responses were on a 5-point scale $(1=$ not at all, $5=$ completely $)$, and the items were mean aggregated with higher scores indicating greater worry at Wave $1(r(3623)=.53, p<.001 ; M=3.66, S D=0.97)$ and over time $(M=3.30, S D=0.98)$.

Sexual Desire. One item was used to assess individuals sexual desire for one's partner (e.g., "In the last two weeks, I felt a great deal of sexual desire for my partner"; adapted from Impett et al., 2008). Possible responses were on a 7-point scale $(1=$ strongly disagree, $7=$ strongly agree), with higher scores indicating more sexual desire for one's partner at Wave 1 ( $M$ $=5.02, S D=1.86)$ and over time $(M=4.88, S D=1.81)$.

Depressive Symptoms. Three items from the Patient Health Questionnaire-4 (PHQ-4; Löwe et al., 2010) were revised to assess experiences of depression since the COVID-19 pandemic began (e.g., "Feeling down, depressed, or hopeless"). Possible responses were on a 5point Likert scale $(0=$ not at all, $4=$ nearly every day $)$, and the items were mean aggregated with higher scores indicating higher depression at Wave $1(\alpha=.77 ; M=2.03, S D=0.76)$ and over time $(M=1.96, S D=0.73)$.

\section{Results}

Reactions to COVID-Related Stressors and Sexual Desire at the Onset of the Pandemic 
The data and syntax for all analyses reported for this paper can be found on the OSF.

Means for each of the focal measures across the waves are presented in Table 2, and correlations between all variables in Study 2 are presented in Table 5.

Using multiple regression, we found that when people reported more stress at onset of the pandemic, they reported feeling less sexual desire for their partner. But, contrary to our predictions, when people reported more loneliness or COVID-related worry, they reported higher sexual desire for their partner than those who reported less loneliness and worry, whereas reports of financial strain were not associated with people's reports of sexual desire for their partner (see Table 6 more details).

\section{Reactions to COVID-Related Stressors and Sexual Desire Overtime}

Next, as in Study 1, we sought to assess within-person changes in COVID-related stressors and sexual desire to test if, at times when people report more stressors than typical, they report lower sexual desire, however, in Study 2, we also sought to assess if these associations were mediated by depressive symptoms overtime. To test these longitudinal effects, we ran a series of multilevel models with each timepoint nested within-person and estimated random intercepts and slopes (Zhang et al., 2009). Predictors were person-mean centered and aggregated, but we focus on the person-mean centered (within-person) effects to test whether changes in COVID-related stressors were associated with changes in sexual desire over the first three months of the pandemic. When people reported more loneliness and stress than their own average, people reported lower sexual desire for their partner. However, no effects emerged for people's financial strain or their worries over themselves or other contracting COVID-19 (see Table 6).

\section{The Role of Depressive Symptoms}


We next tested whether the association between COVID-related stressors and sexual desire overtime was mediated by people's reports of depressive symptoms over the course of the pandemic. To do so, we conducted a series of mediated models using the Monte Carlo Method for Assessing Mediation (MCMAM; Selig \& Preacher, 2008) to test the significance of the indirect effects (using 95\% Confidence Intervals) between COVID-related stressors on sexual desire through reports of depressive symptoms. Results suggest that, in fact, at times when people reported higher loneliness, stress, and more worry about COVID, they reported more depressive symptoms and, in turn, lower sexual desire. That is, there were significant indirect effects from loneliness (95\% CI [-.07, -.02]), stress (95\% CI [-.09, -.01]), worry (95\% CI [-.04, $.01])$, and financial strain (95\% CI [-.03, -.004]) on lower sexual desire through depressive symptoms, although the main effects from financial strain to desire were not significant (see Figures 1A-1D). This pattern of results is consistent with a mediated model and suggests that one reason why COVID-related stressors might be impacting people's sexual desire for their partner's is because people's reactions to COVID-related stressors - like loneliness, stress, and worry — are associated with more depressive symptoms, and depressive symptoms, are in turn associated with lower sexual desire.

\section{Providing Evidence for Generalizability of the Findings}

As in Study 1, we sought to assess whether the association between people's reports of COVID-related stressors and sexual desire differed based on gender or age. Gender did not significantly moderate effects for loneliness, stress, financial strain, or worry about COVID-19 on people's reports of sexual desire at the onset of the pandemic. Similarly, when we examined the effects over time, with one exception, the findings were largely consistent for men and women, although one effect was moderated by gender. More specifically, gender did not 
significantly moderate effects for stress, financial strain, or worry about COVID-19 on people's reports of sexual desire over time. However, gender did moderate the association between loneliness and reports of sexual desire for a partner over time. That is, while women's reports of loneliness were associated with lower desire over time, the association between loneliness and sexual desire was not significant for men (see the Supplemental Materials for more information). Additionally, with one exception, age did not significantly moderate effects for people's reactions to COVID-related stressors on people's reports of sexual desire. More specifically, age did not moderate the effects for stress, financial strain, or worry at the onset of the pandemic over time. However, results suggest that at the onset of the pandemic, age did moderate the association between loneliness and reports of sexual desire, such that the association between loneliness and sexual desire was not significant among individuals who were older $(p=.090)$, but was significant among people who were younger $(b=.11, t(2614)=2.50, \mathrm{p}=.013,95 \% \mathrm{CI}$ $[.02, .20])$. However, this effect was not significant overtime or in Study 1 (see the Supplemental Materials for more information). These results suggest that in this study the associations between COVID-related stressors on people's reports of sexual desire for their partner at the onset of the pandemic and over time are largely consistent across diverse ages and for both men and women, although some difference may occasionally occur.

\section{Discussion}

The current research sought to explore whether emotional reactions to external stressors brought on by COVID-19- such as general levels of stress, loneliness, worry, and financial strain - were associated with lower sexual desire for a romantic partner, and whether this is due to experiencing more depressive symptoms in response to these stressors. Across two studies conducted in the early months of the COVID-19 pandemic - using cross-sectional and 
longitudinal methods - we demonstrated that emotional reactions to COVID-related stressors are associated with people's sexual desire for their partner. More specifically, in the period of time immediately following the onset of the pandemic, more financial concern (Study 1) and worry (Study 2) were associated with higher sexual desire, while other factors, like stress (Studies 1-2), were associated with lower sexual desire. However, when we followed people over time, in most cases, when people experienced more negative emotional reactions to COVID-related stressors than they typically did during the pandemic, they reported lower sexual desire for their partner. Furthermore, we found that depressive symptoms mediated the association between people's emotional reactions to COVID-related stressors and lower sexual desire (Study 2). That is, people who reported more negative reactions to COVID-related stressors reported experiencing greater depressive symptoms, and when people experienced greater depressive symptoms, they in turn, experienced lower sexual desire. Across studies, the results were largely consistent across gender suggesting that the effects of COVID-related stressors on people's reports of sexual desire at onset of the pandemic and over time are consistent for both men and women.

\section{Reactions to COVID-Related Stressors and Sexual Desire}

In the period immediately following the onset of the pandemic, people's emotional reactions to certain stressors were associated with higher sexual desire, while others were associated with lower sexual desire. Although we predicted negative associations between people's emotional reactions to stressors and their reports of sexual desire, there were three instances in which the contrary was true. More specifically, in Study 1, greater financial concern was associated with higher sexual desire, while in Study 2, greater loneliness and more worry about contracting COVID-19 was associated with higher sexual desire for a partner. More consistent with our predictions, we found that heightened reports of stress at the onset of the 
pandemic were associated with lower sexual desire for a romantic partner in Study 1 and Study 2. Additionally, as the pandemic persisted, our results suggest that people's reactions to external stressors were taking a toll on couple's sex lives such that when people experienced greater loneliness (Studies 1-2) and stress (Study 2) they reported less sexual desire for their partner. With regards to why the results are not consistent across the studies, it is possible that this is due, in part, to the studies using different measures. For example, people who are concerned about their finances (assessed in Study 1) may not necessarily be experiencing financial strain (which was assessed in Study 2), and thus these two measures could be tapping into different constructs. Furthermore, the relationship between loneliness and increased desire was observed in Study 2, but not Study 1 (except when looked at within person). However, in Study 2 loneliness was defined by the questions as more relevant to the relationship (e.g., participants were asked to reflect on how "lonely" and "isolated" they have felt in the last two weeks), rather than to a more general feeling of being left out in Study 1 (e.g., participants were asked to reflect on how they felt that they "lack companionship," "left out," and "isolated from others" and these differences in wording could have impacted the results (see the limitations section for further discussion). While there is limited research examining the impact of external stressors on sexual desire, some research suggests that external stressors can negatively contribute to sexual desire (such as minority stress or gendered expectations) whereas other external stressors can positively contribute to sexual desire (such as improved cultural context for sexual expression) depending on the context (Murray et al., 2017; Rosenkrantz \& Mark; 2018). Indeed, considering the positive associations between reactions to COVID-related stressors and desire that emerged at the onset of the pandemic (e.g., worry and loneliness), it is possible that people might experience more sexual desire at times of heightened worry or isolation perhaps to alleviate anxiety and 
stress. However, other work suggests that reactions to external stressors, in particular experiencing high levels of general stress, can dampen people's desire for sex, lower sexual satisfaction, and is associated with higher reports of sexual dysfunction (Bodenmann et al., 2006; Leavitt \& Willoughby, 2015; Montesi et al., 2013; Rokach, 2019), which might help to explain why reports for stress were negatively associated with desire at the onset of the pandemic in the current study, whereas COVID-induced worry and loneliness were positively associated with desire at the onset of the pandemic. Although these findings are interesting, it is unclear why certain types of emotional reactions to stressors may enhance sexual desire at the onset of the pandemic, while others might detract from it, and thus future research is needed to understand when and under what circumstances emotional reactions to external stressors can impact sexual desire for a romantic partner.

Importantly, past research has rarely examined the effect of people's emotional reactions to external stressors on sexual desire and functioning over time, which may explain the mixed empirical findings in the literature on how and when stressors can impact people's sexual desire. The present work indeed indicates that changes in emotional reactions to COVID-related stressors were associated with lower sexual desire for a partner over time, suggesting a difference between immediate effects of stressors and changes in emotional reactions over time on sexual desire for people in romantic relationships. In fact, although no research has previously examined the effects of loneliness on sexual desire and there is limited research examining the effects of stress on sexual desire, in both studies, we see that changes in loneliness over the first couple of months of the pandemic were associated with people reporting lower desire for their partner, and in Study 2, changes in reports of stress were associated with lower sexual desire. This is in line with the Dual Control Model (Bancroft \& Janssen, 2000; Bancroft et al., 2009), 
that suggests that if there are too many external stressors piling up it will inhibit sexual responses, dampening desire. So, while the unfamiliar and new changes that were introduced due to COVID-19 might have had some initial positive effects (e.g., changing one's routine and being cooped up at home with a partner in quarantine may be fun at first but lose its appeal overtime), for many, these changes might have become distressing as time went on.

The current research offers a unique opportunity to examine the role that people's reactions to external stressors play in people's most intimate lives and offers an explanation as to why and when stress can dampen desire in romantic relationships. Given the dearth of information about how external stressors are associated with sexual desire in the context of longterm relationships, this research provides an important contribution, particularly given that even outside of the COVID-19 pandemic, couples cope with external stressors over the course of their relationship (i.e., job loss, stress related to work-life balance, family illnesses, and so forth). The current findings suggest that during times when people face more stress and feel lonelier, this might be linked to lower sexual desire overtime. Future work should consider how people can best cope with external stressors and what factors might help buffer the detriments of external stressors on sexual desire in relationships. Furthermore, an important future direction will be examining these effects among both partners in a relationship to see how one partner's experiences might shape the other, and to understand what partners can do to mitigate the effects.

\section{Mediating Effect of Depressive Symptoms}

In the current study we explored whether one reason why COVID-related stressors are associated with lower levels of sexual desire over time is because such stressors are associated with increased depressive symptoms, and that increases in depressive symptoms are, in turn, associated with decreased desire for one's romantic partner. We found that the association 
between greater COVID-related stressors (e.g., loneliness, stress, financial strain, and worry) and lower sexual desire was mediated by people's reports of depressive symptoms (assessed in Study 2 only). Thus, consistent with our predictions, people who reported more COVID-related stressors reported experiencing greater depressive symptoms, and when people experienced greater depressive symptoms, they in turn, experienced lower sexual desire. Additionally, it is also worth noting that in the mediation models, depression was consistently associated with lower reports of sexual desire. This corroborates and extends past research that has shown that people who experience negative life events often experience heightened levels of depression (e.g., Kopala-Sibley et al., 2016; Spinhoven et al., 2011), and other research showing that depressive symptoms are linked to lower levels of desire and sexual functioning (Kalmbach et al., 2015). However, this research is among the first to simultaneously examine the role of various external stressors on sexual desire and the mediating effects of depressive symptoms. Furthermore, this research extends recent work that has shown that people are experiencing higher levels of depressive symptoms and other mental health challenges during the COVID-19 pandemic (Bueno-Notivol et al., 2021), by showing that external stressors and experiences of psychological burden brought on by the COVID-19 pandemic are also linked to the most intimate aspects of people's relationships.

\section{Implications, Limitations, and Future Directions}

These results provide some initial evidence for the effects of people's reactions to external stressors introduced during the COVID-19 pandemic - such as loneliness, stress, worry, and financial concern — on people's sexual desire for their partner. The current set of studies have several strengths, including examining the association between people's reactions to external stressors and depressive symptoms on sexual desire for a romantic partner, during a 
stressful experience (i.e., amidst an international pandemic). As well as by examining the associations in two large, independent pre-registered studies designed to assess within-person changes over time. However, several limitations should also be noted. First, we used self-report measures to assess people's COVID-related stressors, depressive symptoms, and sexual desire for their partner in these studies. Using self-report measures is limiting as some research suggests that self-report measures show only modest convergence with interview-based measures and may be prone to errors and biases in the recall and reporting of life stressors (see Monroe, 2008 for a discussion of these issues). Second, as with any study, the scope of this research is limited by the measures included. That is, we did not include measures to assess clinical levels of depression or low desire, and we did not assess people's desire towards sex more generally. Thus, we do not know if our results would extend to diagnoses of major depression or sexual desire disorder, nor do we know if people's prolonged exposure to COVID-related stressors and experiences of depressive symptoms might have led to increases in clinical levels of depression or less desire towards sex more generally (e.g., not be partner specific). In the current research we focused on people's sexual desire for their partner, though sexual desire is often associated with other aspects of sexual functioning (e.g., Gerstenberger, Rosen, Brewer, Meston, Brotto, Wiegel, \& Sand, 2010; Kim, 2013; Mark, 2012) as well as sexual frequency (e.g., Beutel et al., 2008; Lehmiller et al., 2020) — thus, these are all important questions to be answered in future research. Fourth, there are some discrepancies in the measures employed in the two studies used to test our hypotheses. That is, because the data for each study was collected by separate research teams, there were several differences in the measures included. For example, in Study 1, we assessed financial concern, whereas in Study 2 we assessed financial strain. Additionally, in Study 1 , there were no attention checks included and thus we cannot speak to whether some 
participants in that study were (or were not) fully attentive in their responding. Furthermore, we cannot rule out some non-independence of data. It is possible that participants could have shared the study with their partner(s) who also participated, and it is possible people could have participated in both studies. Finally, although this research provides important insights into sexual desire over the course of the pandemic using geographically diverse samples, it is important to note that when disasters occur, everyone in a community is affected, though not equally. As such, future research is needed to help illustrate whether differences in economic circumstances, or sociodemographic factors, for example, impacted people's experiences coping with COVID-19 and thus had differential, or perhaps more detrimental impacts, on their depressive symptoms and sexual desire.

\section{Conclusion}

Stressful events are inevitable, can be difficult to manage, and can take a toll on people's sexual desire for their partner over time. In the current research, we find that following the onset of the pandemic, certain factors like financial concern, loneliness, and worry over COVID-19 were associated with increased sexual desire, while other factors like stress were associated with decreased desire for a romantic partner. When we examined these effects over time, results suggest that changes in loneliness (Studies 1-2) and stress (Study 2) were associated with reports of lower sexual desire for one's partner. Furthermore, we demonstrate that depressive symptoms mediated the association between COVID-related stressors and sexual desire for a partner (Study 2). That is, when people reported more stress, loneliness, financial strain, or worry than their average, this was associated with greater depressive symptoms, and when people experienced greater depressive symptoms, they in turn, experienced lower sexual desire. Based on the current findings, the COVID-19 pandemic, although initially thought to provide more sexual 
opportunities for couples (e.g., Bakar, 2020; Fordham, 2020; Whittle, 2020), seems to be taking a negative toll on people's sex lives, and this is in part because of the new stressors it has brought on and the challenges that such stressors have had on people's well-being. 


\section{References}

Ahmed, M. Z., Ahmed, O., Zhou, A., Sang, H., Liu, S., \& Ahmad, A. (2020). Epidemic of COVID-19 in China and associated psychological problems. Asian Journal of Psychiatry, 51, Advance Online Publication.

Aksaray, G., Yelken, B., Kaptanoglu, C., Oflu, S., \& Özaltin, M. (2001). Sexuality in women with obsessive compulsive disorder. Journal of Sex and Martial Therapy, 27, 273-277.

Apt, C., Hurlbert, D. F., Pierce, A. P., \& White, L. C. (1996). Relationship satisfaction, sexual characteristics and the psychosocial well-being of women. Canadian Journal of Human Sexuality, 5, 195-210.

Baggett, L. R., Eisen, E., Gonzalez-Rivas, S., Olson, L. A., Cameron, R. P., \& Mona, L. R. (2017). Sex-positive assessment and treatment among female trauma survivors. Journal of Clinical Psychology, 73, 965-974.

Bakar, F. (2020). Are we going to see a coronavirus baby boom? Metro. Retrieved from https://metro.co.uk/2020/03/31/going-see-coronavirus-baby-boom-12484432/

Balzarini, R. N., Muise, A., Zoppolat, G., Di Bartolomeo, A., Rodrigues, D. L., Alonso-Ferres, M., Urganci, B., Debrot, A., Pichayayothin, N. B., Dharma, C., Chi, P., Karremans, J., Schoebi, D., \& Slatcher, R. B. (2022). Love in the time of COVID: Perceived partner responsiveness buffers people from lower relationship quality associated with COVIDrelated stressors. PsyArXiv.

Bancroft, J., Graham, C. A., Janssen, E., \& Sanders, S. A. (2009). The Dual Control Model: Current Status and Future Directions. Journal of Sex Research, 46, 121-142.

Bancroft, J., \& Janssen, E. (2000). The Dual Control Model of male sexual response: A theoretical approach to centrally mediated erectile dysfunction. Neuroscience and Biobehavioral Reviews, 24, 571-579. 
Basson, R. (2001). Using a different model for female sexual response to address women's problematic low sexual desire. Journal of Sex and Marital Therapy, 27, 395-403.

Basson, R. (2008). Women's sexual function and dysfunction: current uncertainties, future directions. International Journal of Impotence Research, 20, 466-478.

Beutel, M. E., Stöbel-Richter, Y., \& Brähler, E. (2008). Sexual desire and sexual activity of men and women across their lifespans: results from a representative German community survey. British Journal of Urology International, 101, 76-82.

Birnbaum, G. E., Hirschberger, G., \& Goldenberg, J. L. (2011). Desire in the face of death: Terror management, attachment, and sexual motivation. Personal Relationships, 18, 119.

Bodenmann, G. (1997). The influence of stress and coping on close relationships: A two year longitudinal study. Swiss Journal of Psychology, 56, 156-164.

Bodenmann, G., Ledermann, T., Blattner-Bolliger, D., \& Galluzzo, C. (2006). The associations among everyday stress, critical life events and sexual problems. Journal of Nervous and Mental Disease, 194, 494-501.

Bolger, N., Davis, A., \& Rafaeli, E. (2003). Diary methods: Capturing life as it is lived. Annual Review of Psychology, 54, 579-616.

Bolger, N., DeLongis, A., Kessler, R. C., \& Wethington, E. (1989). The contagion of stress across multiple roles. Journal of Marriage and the Family, 51, 175-183.

Bridges, S. K., \& Horne, S. G. (2007). Sexual satisfaction and desire discrepancy in same-sex women's relationships. Journal of Sex and Marital Therapy, 33, 41-53. 
Brooks, S. K., Webster, R. K., Smith, L. E., Woodland, L., Wessely, S., Greenberg, N., et al. (2020). The psychological impact of quarantine and how to reduce it: Rapid review of the evidence. Lancet, 395, 912-920.

Buck, A. A. \& Neff, L. A. (2012). Stress spillover in early marriage: The role of self-regulatory depletion. Journal of Family Psychology, 26, 698-708.

Bueno-Notivol, J., Gracia-García, P., Olaya, B., Lasheras, I., López-Antón, R., \& Santabárbara, J. (2021). Prevalence of depression during the COVID-19 outbreak: a meta-analysis of community-based studies. International Journal of Clinical and Health Psychology, 21, Advance Online Publication.

Cacioppo, J. T., Chen, H. Y., \& Cacioppo, S. (2017). Reciprocal influences between loneliness and self-centeredness: A cross-lagged panel analysis in a population-based sample of African American, Hispanic, and Caucasian adults. Personality and Social Psychology Bulletin, 43, 1125-1135.

Cacioppo, J. T., Hawkley, L. C., \& Thisted, R. A. (2010). Perceived social isolation makes me sad: 5-year cross-lagged analyses of loneliness and depressive symptomatology in the Chicago Health, Aging, and Social Relations Study. Psychology and Aging, 25, 453463.

Cacioppo, J. T., Hughes, M. E., Waite, L. J., Hawkley, L. C., \& Thisted, R. A. (2006). Loneliness as a specific risk factor for depressive symptoms: Cross sectional and longitudinal analyses. Psychology and Aging, 21, 140-151.

Carlson, D. L., Petts, R., \& Pepin, J. R. (2020). US couples' division of housework and childcare during COVID-19 pandemic. Retrieved from https://osf.io/preprints/socarxiv/jy8fn. 
Çayan, S., Akbay, E., Bozlu, M., Canpolat, B., Acar, D., \& Ulusoy, E. (2004). The prevalence of female sexual dysfunction and potential risk factors that may impair sexual function in Turkish women. Urologic Internationalis, 72, 52-57.

Cellini, N., Canale, N., Mioni, G., \& Costa. S. (2020). Changes in sleep pattern, sense of time and digital media use during COVID-19 lockdown in Italy. Journal of Sleep Research, 29, e13074.

Cito, G., Micelli, E., Cocci, A., Polloni, G., Russo, G. I., Coccia, M. E., et al. (2021). The impact of the COVID-19 quarantine on sexual life in Italy. Urology, 147, 37-42.

Cocci, A., Giunti, D., Tonioni, C., Cacciamani, G., Tellini, R., Polloni, G., Cito, G., Presicce, F., Di Mauro, M., Minervini, A., Cimino, S., \& Russo, G. I. (2020). Love at the time of the COVID-19 pandemic: Preliminary results of an online survey conducted during the quarantine in Italy. International Journal of Impotence Research, 32, 556-557.

Cohen, S., Kamarck, T., \& Mermelstein, R. (1983). A global measure of perceived stress. Journal of Health and Social Behavior, 24, 385-396.

Colina, S., Marrone, N., Ingram, M., \& Sanchez, D. (2017). Translation quality assessment in health research: A functionalist alternative to back-translation. Evaluation \& the Health Professions, 40, 267-293.

Conger, R. D., Rueter, M. A., \& Elder, G. H. (1999). Couple resilience to economic pressure. Journal of Personality and Social Psychology, 76, 54-71.

Congressional Research Service. (2020). Global Economic Effects of COVID-19. Retrieved from https://fas.org/sgp/crs/row/R46270.pdf. 
Coyle, D. (2020). Odds released on Trojan Condom stock price and US birth rate in 2020. SportsBettingDime. Retrieved from https://www.sportsbettingdime.com/news/oddsreleased-trojan-condom-stock-price-us-birth-rate-2020/

Davies, S., Katz, J., \& Jackson, J. L. (1999). Sexual desire discrepancies: Effects on sexual and relationship satisfaction in heterosexual dating couples. Archives of Sexual Behavior, 28, $553-567$.

Davison, S. L., Bell, R. J., LaChina, M., Holden, S. L., \& Davis, S. R. (2009). The relationship between self-reported sexual satisfaction and general well-being in women. Journal of Sexual Medicine, 6, 2690-2697.

De Wolfe, D. J. (2000). Training manual for mental health and human service workers in major disasters (Publication No. ADM 90 -538). Washington, DC: U.S. Government Printing Office, U.S. Department of Health and Human Services: Center for Mental Health Services.

Dobkin, R., Leiblum, S. R., Rosen, R. C., Me0nza, M., \& Marin, H. (2006). Depression and sexual functioning in minority women: Current status and future directions. Journal of Sex and Marital Therapy, 32, 23-36.

Erdfelder, E., Faul, F., \& Buchner, A. (1996). GPOWER: a general power analysis program. Behavior Research Methods, Instruments, \& Computers, 28, 1-11.

Ervasti, H. \& Venetoklis, T. (2010). Unemployment and subjective well-being: an empirical test of deprivation theory, incentive paradigm and financial strain approach. Acta Sociologica $53,119-138$.

Faria e Castro, M. (2020). Fiscal policy during a pandemic. Federal Reserve Bank of St. Louis. Retrieved from https://s3.amazonaws.com/real.stlouisfed.org/wp/2020/2020-006.pdf 
Faul, F., Erdfelder, E., Buchner, A., \& Lang, A. G. (2009). Statistical power analyses using G* Power 3.1: tests for correlation and regression analyses. Behavior Research Methods, 41, $1149-1160$.

Fernández-Aranda, F., Casas, M., Claes, L., Bryan, D. C., Favaro, A., Granero, R., ... Treasure, J. (2020). COVID -19 and implications for eating disorders. European Eating Disorders Review, 28, 239-245.

Fordham, E. (2020). Will coronavirus cause a baby boom? Fox Business. Retrieved from https://www.foxbusiness.com/lifestyle/coronavirus-baby-boom-covid-19-1

Gangopadhyaya, A., \& Garrett, B. (2020). Unemployment, Health Insurance, and the COVID19 Recession. Urban Institute.

Gerstenberger, E. P., Rosen, R. C., Brewer, J. V., Meston, C. M., Brotto, L. A., Wiegel, M., \& Sand, M. (2010). Sexual desire and the Female Sexual Function Index (FSFI): A sexual desire cutpoint for clinical interpretation of the FSFI in women with and without hypoactive sexual desire disorder. The Journal of Sexual Medicine, 7, 3096-3103.

Gordon, A., Cross, E., Ascigil, E., Balzarini, R. N., Luerssen, A., \& Muise, A. (2022). Feeling appreciated buffers against the negative effects of unequal division of household labor on relationship satisfaction. Psychological Science, Advanced online publication.

Hakulinen, C., Pulkki-Råback, L., Virtanen, M., Jokela, M., Kivimäki, M., \& Elovainio, M. (2018). Social isolation and loneliness as risk factors for myocardial infarction, stroke and mortality: UK Biobank cohort study of 479054 men and women. Heart, 104, 15361542.

Kopala-Sibley, D. C., Danzig, A. P., Kotov, R., Bromet, E. J., Carlson, G. A., Olino, T. M., Bhatia, V., Black, S. R., \& Klein, D. N. (2016). Negative emotionality and its facets 
moderate the effects of exposure to Hurricane Sandy on children's postdisaster depression and anxiety symptoms. Journal of Abnormal Psychology, 125, 471-481.

Hall, K. S, Kusunoki, Y., Gatny, H., \& Barber, J. (2014). Stress symptoms and frequency of sexual intercourse among young women. The Journal of Sexual Medicine, 11, 19821990.

Hamilton, L. D., \& Julian, A. M. (2014). The relationship between daily hassles and sexual function in men and women. Journal of Sex \& Marital Therapy, 40, 379-395.

Hamilton, L. D., \& Meston, C. M. (2013). Chronic stress and sexual function in women. The Journal of Sexual Medicine, 10, 2443-2454.

Hammen, C. (2005). Stress and depression. Annual Review of Clinical Psychology, 1, 293319.

Hartmann, U. (2007). Depression and sexual dysfunction. The Journal of Men's Health and Gender, 4, 18-25.

Holt-Lunstad, J., Smith, T. B., Baker, M., Harris, T., \& Stephenson, D. (2015). Loneliness and social isolation as risk factors for mortality: A meta-analytic review. Perspectives on Psychological Science, 10, 227- 237.

Huang, Y., \& Zhao, N. (2020). Generalized anxiety disorder, depressive symptoms and sleep quality during COVID-19 epidemic in China: A web-based cross-sectional survey. Psychiatry Research, 288, e112954.

Impett, E. A., Strachman, A., Finkel, E. J., \& Gable, S. L. (2008). Maintaining sexual desire in intimate relationships: The importance of approach goals. Journal of Personality and Social Psychology, 94, 808-823. 
Kalmbach, D. A., Ciesla, J. A., Janata, J. W., \& Kingsberg, S. A. (2015). The validation of the Female Sexual Function Index, Male Sexual Function Index, and Profile of Female Sexual Function for use in healthy, young adults. Archives of Sexual Behavior, 44, 16511662.

Karney, B. R., Story, L. B., \& Bradbury, T. N. (2005). Marriages in context: Interactions between chronic and acute stress among newlyweds. In T. A. Revenson, K. Kayser, \& G. Bodenmann (Eds.). Couples coping with stress: Emerging perspectives on dyadic coping (pp. 13-32). American Psychological Association Press.

Kim, H. (2013). Sexual desire, sexual function, and quality of life in married women with hypoactive sexual desire disorder. Korean Journal of Health Education and Promotion, $30,163-175$.

King, A. (2020). Official unemployment numbers don't show the true crisis for workers affected by coronavirus. The Conversation. Retrieved from https://theconversation.com/officialunemployment-numbers-dont-show-the-true-crisis-for-workers-affected-by-coronavirus136110

Kochhar, R. (2020). Unemployment rose higher in three months of COVID-19 than it did in the years of the Great Recession. Pew Research Center. Retrieved from https://www.pewresearch.org/fact-tank/2020/06/11/unemployment-rose-higher-in-threemonths-of-covid-19-than-it-did-in-two-years-of-the-great-recession/

Kontula, O., \& Haavio-Mannila, E. (2009). The impact of aging on human sexual activity and sexual desire. Journal of Sex Research, 46, 46-56.

Koo, J. R., Cook, A. R., \& Park, M. (2020). Interventions to mitigate early spread of COVID-19 in Singapore: a modelling study. Lancet Infectious Diseases, 20, 678-688. 
Kowal, M., Coll-Martín, T., Ikizer, G., Rasmussen, J., Eichel, K., Studzińska, A., Koszałkowska, K., Karwowski, M., Najmussaqib, A., Pankowski, D., Lieberoth, A., \& Ahmed, O. (2020). Who is the most stressed during the COVID-19 pandemic? Data from 26 countries and areas. Applied Psychology: Health and Well-Being, 12234.

Layden, E. A., Cacioppo, J. T., \& Cacioppo, S. (2018). Loneliness predicts a preference for larger interpersonal distance within intimate space. PLOS One, 13, e0203491.

Laumann, E. O., Paik, A., \& Rosen, R. C. (1999). Sexual dysfunctions in the United States: Prevalence and predictors. Journal of the American Medical Association, 281, 537-544.

Leavitt, C. E., \& Willoughby, B. J. (2015). Associations between attempts at physical intimacy and relational outcomes among cohabiting and married couples. Journal of Social and Personal Relationships, 32, 241-262.

Lehmiller, J. J., Garcia, J. R., Gesselman, A. N., \& Mark, K. P. (2020). Less sex, but more sexual diversity: Changes in sexual behavior during the COVID-19 coronavirus pandemic. Leisure Sciences, Advance online publication.

Lewnard, J. A. \& Lo, N. C. (2020). Scientific and ethical basis for social-distancing interventions against COVID-19. Lancet Infectious Diseases, 20, 631-633.

Li, G., Tang, D., Song, B., Wang, C., Qunshan, S., Xu, C., Geng, H., Wu, H., He, X., \& Cao, Y. (2020). Impact of the COVID-19 pandemic on partner relationships and sexual and reproductive health: Cross-sectional, online survey study. Journal of Medical Internet Research, 22, e20961.

Lopes, G. P., Vale, F. B. C., Vieira, I., da Silva Filho, A. L., Abuhid, C., \& Geber, S. (2020). COVID-19 and sexuality: Reinventing intimacy. Archives of Sexual Behavior, 49, 27352738. 
Löwe, B., Wahl, I., Rose, M., Spitzer, C., Glaesmer, H., Wingenfeld, K., et al. (2010). A 4-item measure of depression and anxiety: Validation and standardization of the Patient Health Questionnaire-4 (PHQ-4) in the general population. Journal of Affective Disorders, 122, $86-95$.

Mark, K. P. (2012). The relative impact of individual sexual desire and couple desire discrepancy on satisfaction in heterosexual couples. Sexual and Relationship Therapy, 27, 133-146.

Mark, K. P. (2014). The impact of daily sexual desire and daily sexual desire discrepancy on the quality of the sexual experience in couples. Canadian Journal of Human Sexuality, 23, $27-33$.

Mark, K. P., \& Murray, S. H. (2012). Gender differences in desire discrepancy as a predictor of sexual and relationship satisfaction in a college sample of heterosexual romantic relationships. Journal of Sex and Marital Therapy, 38, 198-215.

Martin, S. A., Atlantis, E., Lange, K., et al (2014). Predictors of sexual dysfunction incidence and remission in men. Journal of Sexual Medicine, 11, 1136-1147.

Mellor, M. (2020). Coronavirus has created a sex toy boom. A baby boom may not follow. Wired. Retrieved from https://www.wired.co.uk/article/coronavirus-pandemic-sex-toys Mestre-Bach, G., Blycker, G. R., \& Potenza, M. N. (2020). Pornography use in the setting of the COVID-19 pandemic. Journal of Behavioral Addictions, 9, 181-183.

Michael, A., \& O'Keane, V. (2000). Sexual dysfunction in depression. Human Psychopharmacology, 15, 337-345.

Minnen, A., \& Kampman, M. (2000). The interaction between anxiety and sexual functioning: A controlled study of sexual functioning in women with anxiety disorders. Sexual and Relationship Therapy, 15, 47-57. 
Mitchell, K. R., Wellings, K. A., \& Graham, C. (2014). How do men and women define sexual desire and sexual arousal?. Journal of Sex \& Marital Therapy, 40, 17-32.

Monroe, S. M. (2008). Modern approaches to conceptualizing and measuring human life stress. Annual Review in Clinical Psychology, 4, 33-52.

Montesi, J. L., Conner, B. T., Gordon, E. A., Fauber, R. L., Kim, K. H., \& Heimberg, R. G. (2013). On the relationship among social anxiety, intimacy, sexual communication, and sexual satisfaction in young couples. Archives of Sexual Behavior, 42, 81-91.

Morokoff, P. J., \& Gillilland, R. (1993). Stress, sexual functioning, and marital satisfaction. Journal of Sex Research, 30, 43-53.

Mund, M., Weidmann, R., Wrzus, C., Johnson, M. D., Bu“hler, J. L., Burriss, R. P., Wu“nsche, J., \& Grob, A. (2022). Loneliness is associated with the subjective evaluation of but not daily dynamics in partner relationships. International Journal of Behavioral Development, 46, 28-38.

Murray, S. H., Milhausen, R. R., Graham, C. A., \& Kuczynski, L. (2017). A qualitative exploration of factors that affect sexual desire among men aged 30 to 65 in long-term relationships. Journal of Sex Research, 54, 319-330.

Neff, L. A., \& Karney, B. R. (2017). Acknowledging the elephant in the room: How stressful environmental contexts shape relationship dynamics. Current Opinions in Psychology, 13, 107-110.

Okechukwu, C. A., El Ayadi, A. M., Tamers, S. L., Sabbath, E. L., \& Berkman, L. (2012). Household food insufficiency, financial strain, work-family spillover, and depressive symptoms in the working class: The Work, Family, and Health Network study. American Journal of Public Health, 102, 126-133. 
Pappas, S. (2020). How will people react to the new financial crisis? American Psychological Association. Retrieved from https://www.apa.org/news/apa/2020/04/financial-crisisCOVID-19

Pearlin, L. I., Lieberman, M. A., Menaghan, E. G., \& Mullan, J. T. (1981). The stress process. Journal of Health and Social Behavior, 22, 337-356.

Peplau, L. A. (2003). Human sexuality: How do men and women differ?. Current Directions in Psychological Science, 12, 37-40.

Pornhub Insights. (2020). Coronavirus update-April 14. Pornhub. Retrieved from https://www.pornhub.com/insights/coronavirus-update-april-14

Pyszczynski, T., Solomon, S., \& Greenberg, J. (2015). Thirty years of Terror Management Theory: From genesis to revelation. In J. M. Olson \& M. P. Zanna (Eds.), Advances in Experimental Social Psychology (Vol. 52, pp. 1-70). Academic Press.

Qualter, P., Vanhalst, J., Harris, R., van Roekel, E., Lodder, G., Bangee, M., Maes, M., \& Verhagen, M. (2015). Loneliness across the life span. Perspectives on Psychological Science, 10, 250-264.

Randall, A. K. \& Bodenmann, G. (2009). The role of stress on close relationships and marital satisfaction. Clinical Psychology Review, 29, 105-115.

Rokach, A. (2019). The effect of psychological conditions on sexuality: a review. Psychology and Psychotherapy: Research Study, 2, 1-2.

Rosenkrantz, D. E., \& Mark, K. P. (2018). The sociocultural context of sexually diverse women's sexual desire. Sexuality \& Culture, 22, 220-242.

Santtila, P., Wager, I., Witting, K., Harlaar, N., Jern, P., Johansson, A. D. A., \& Sandnabba, N. K. (2007). Discrepancies between sexual desire and sexual activity: Gender differences 
and associations with relationship satisfaction. Journal of Sex and Marital Therapy, 34, $31-44$.

Schnurr, P., Lunney, C., Forshay, E., Thurston, V., Chow, B., Resick, P., \& Foa, E. (2009). Sexual function outcomes in women treated for posttraumatic stress disorder. Journal of Women's Health, 18, 1549-1557.

Segraves, R. T. (2002). Female sexual disorders: Psychiatric aspects. Canadian Journal of Psychiatry, 47, 419-425.

Selig, J. P., \& Preacher, K. J. (2008). Monte Carlo method for assessing mediation: An interactive tool for creating confidence intervals for indirect effects [Computer software]. Retrieved from http://quantpsy.org/

Slavich, G. M. \& Irwin, M. R. (2014). From stress to inflammation and major depressive disorder: A social signal transduction theory of depression. Psychological Bulletin, 140, 774-815.

Spinhoven, P., Elzinga, B. M., Hovens, J. G., Roelofs, K., van Oppen, P., Zitman, F. G., \& Penninx, B. W. (2011). Positive and negative life events and personality traits in predicting course of depression and anxiety. Acta Psychiatrica Scandinavica, 124, 462473.

Story, L. B., \& Bradbury, T. N. (2004). Understanding marriage and stress: Essential questions and challenges. Clinical Psychology Review, 23, 1139-1162.

Tian, F., Li, H., Tian, S., Yang, J., Shao, J., \& Tian, C. (2020). Psychological symptoms of ordinary Chinese citizens based on SCL-90 during the level I emergency response to COVID-19. Psychiatry Research Neuroimaging, 288, Advance Online Publication. 
Tyupa, S. (2011). A theoretical framework for back-translation as a quality assessment tool. New Voices in Translation Studies, 7, 35-46.

Watson, D., \& Clark, L. A. (1999). The PANAS-X: Manual for the positive and negative affect schedule-expanded form.Panzeri, M., Ferrucci, R., Cozza, A., \& Fontanesi, L. (2020). Changes in sexuality and quality of couple relationship during the COVID-19 lockdown. Frontiers in Psychology, 11, e565823.

Wei, M., Russell, D. W., \& Zakalik, R. A. (2005). Adult attachment, social self-efficacy, selfdisclosure, loneliness, and subsequent depression for freshmen college students: A longitudinal study. Journal of Counseling Psychology, 524, 602-614.

Whittle, P. (2020). Coronavirus baby boom another curve that could be flattened. ABC News. Retrieved from https://abcnews.go.com/Health/wireStory/coronavirus-baby-boom-curveflattened-69674351

Yuksel, B. \& Ozgor, F. (2020). Effect of the COVID-19 pandemic on female sexual behavior. International Journal of Gynecology and Obstetrics, 150, 98-102.

Zhang, Z., Zyphur, M. J., \& Preacher, K. J. (2009). Testing multilevel mediation using hierarchical linear models: Problems and solutions. Organizational Research Methods, 12, 695-719.

Zimmerman, F., \& Katon, W. (2005). Socioeconomic status, depression disparities, and financial strain: what lies behind the income-depression relationship? Health Economics, 14, $1197-1215$.

Zunin, L. M. \& Myers, D. (2000), Training Manual for Human Service Workers in Major Disasters (2nd ed.). Department of Health and Human Services, Substance Abuse and 
Mental Health Services Administration, Center for Mental Health Services, Washington, DC. 


\section{Tables}

Table 1

Demographic Information for Study 1 and Study 2

\begin{tabular}{|c|c|c|}
\hline & Study 1 & Study 2 \\
\hline Age - Mean (SD) & $36.10(10.99)$ & $32.97(12.57)$ \\
\hline Relationship Length - Mean (SD) & $9.22(8.77)$ & $8.30(9.99)$ \\
\hline \multicolumn{3}{|l|}{ Gender } \\
\hline Male & $364(26.7 \%)$ & $759(21.0 \%)$ \\
\hline Female & $948(69.6 \%)$ & $2,828(78.1 \%)$ \\
\hline Other & $50(3.6)$ & $33(0.9 \%)$ \\
\hline \multicolumn{3}{|l|}{ Sexual Orientation } \\
\hline Heterosexual & $810(59.4 \%)$ & $3,021(83.6 \%)$ \\
\hline Lesbian/Gay & $75(5.5 \%)$ & $155(4.3 \%)$ \\
\hline Bisexual & $259(19.0 \%)$ & $372(10.3 \%)$ \\
\hline Other & $220(16.1 \%)$ & $65(1.8 \%)$ \\
\hline \multicolumn{3}{|l|}{ Relationship Status } \\
\hline Dating & $535(39.1 \%)$ & $1,962(54.2 \%)$ \\
\hline Engaged & $115(8.4 \%)$ & $317(8.7 \%)$ \\
\hline Married & $717(52.5 \%)$ & $1345(37.1 \%)$ \\
\hline Other & - & - \\
\hline
\end{tabular}


Table 2

Sample Size and Means (and Standard Deviations) of Focal Variables for Study 1 and 2 Over the Course of the Study

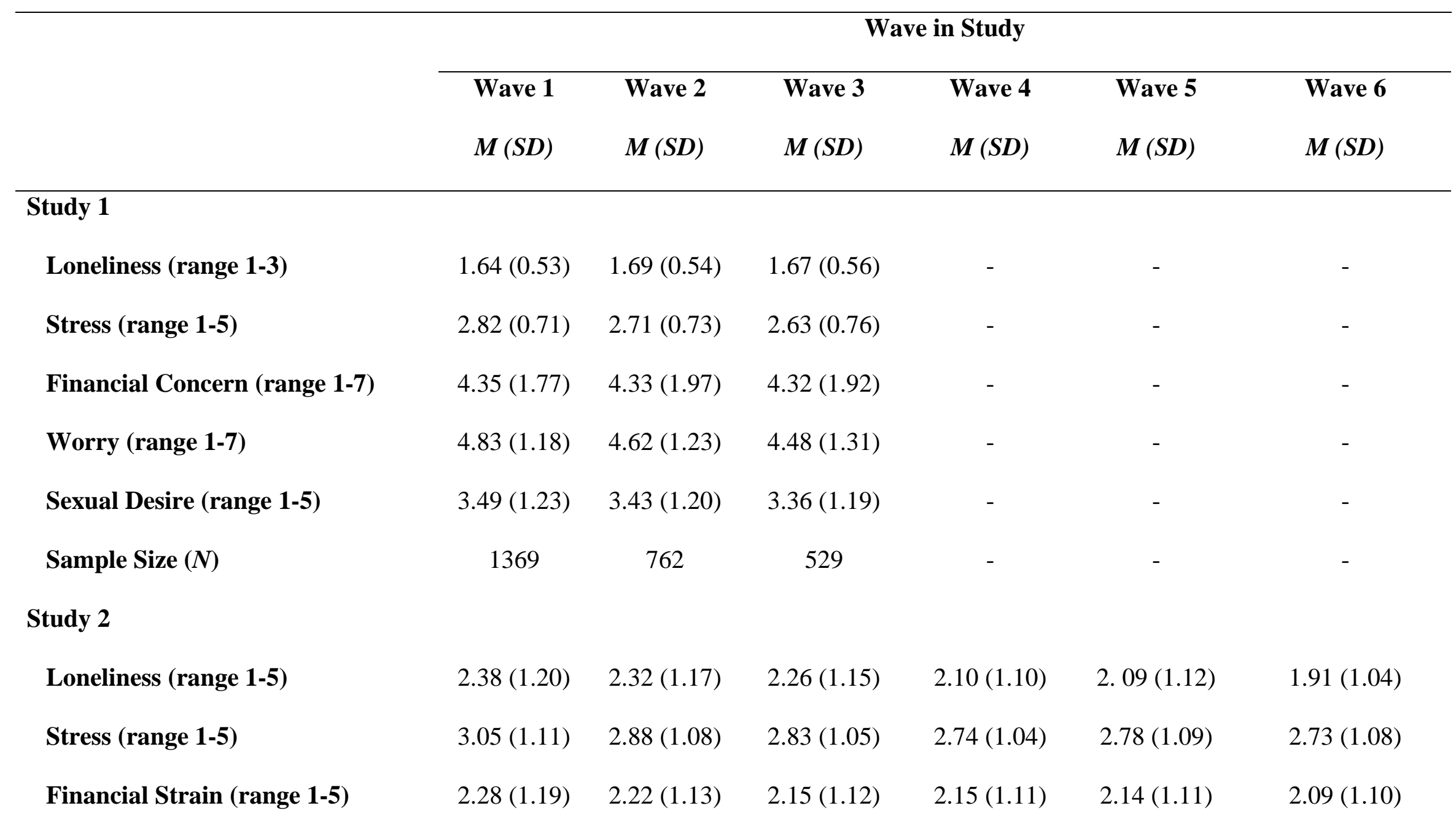




\begin{tabular}{|c|c|c|c|c|c|c|}
\hline Worry (range 1-5) & $3.55(0.95)$ & $3.37(0.95)$ & $3.24(0.99)$ & $3.15(0.98)$ & $3.14(1.01)$ & $3.12(0.98)$ \\
\hline Depressive Symptoms (range 1-4) & $2.02(0.75)$ & $1.99(0.74)$ & $1.97(0.73)$ & $1.91(0.71)$ & $1.91(0.74)$ & $1.85(0.73)$ \\
\hline Sexual Desire (range 1-7) & $4.90(1.85)$ & $4.82(1.80)$ & $4.86(1.79)$ & $4.93(1.77)$ & $4.81(1.79)$ & $4.99(1.80)$ \\
\hline Sample Size $(N)$ & 3,565 & 944 & 886 & 692 & 570 & 452 \\
\hline
\end{tabular}

Note: Study 1 only examined measures from the first three waves of the study, whereas Study 2 includes assessments from six waves.

In all instances, higher means indicate greater endorsement for that variable. 
Table 3

Correlations Among Focal Variables for Study 1

\begin{tabular}{lccccc}
\hline & $\mathbf{1}$ & $\mathbf{2}$ & $\mathbf{3}$ & $\mathbf{4}$ & $\mathbf{5}$ \\
\hline 1. Loneliness & - & & & & \\
2. Stress & $.48^{* * *}$ & - & & & \\
3. Financial Concern & $.18^{* * *}$ & $.11 * * *$ & - & & \\
4. Worry & $.10^{* * *}$ & .02 & $.31 * * *$ & - & \\
5. Sexual Desire & $-.16^{* * *}$ & $.28 * * *$ & $.05 *$ & -.01 & -
\end{tabular}

Note: $* * * p<.001, * * p<.01, * p<.05$. Variables were assessed at all waves (bi-weekly) and aggregated across waves. 
Table 4

Main Effect Models with Reports of COVID-Related Stressors (Loneliness, Stress, Financial Concern, and Worry) Predicting Dyadic Sexual Desire and Desire for a Romantic Partner in Study 1

Sexual Desire

\begin{tabular}{lccc|ccc} 
& \multicolumn{3}{c|}{ Wave 1 } & \multicolumn{3}{c}{ Overtime } \\
\cline { 2 - 6 } & $\boldsymbol{b}$ & $\boldsymbol{S E}$ & $\boldsymbol{C I}$ & $\boldsymbol{b}$ & $\boldsymbol{S E}$ & $\boldsymbol{C I}$ \\
Loneliness & -.10 & .07 & $-.24, .04$ & $-.08 * *$ & .03 & $-.12,-.03$ \\
Stress & $-.27^{* * *}$ & .06 & $-.38,-.16$ & -.01 & .01 & $-.03, .01$ \\
Financial Concern & $.06^{* *}$ & .02 & $.02, .10$ & .03 & .03 & $-.03, .10$ \\
Worry & .01 & .03 & $-.06, .07$ & .03 & .03 & $-.03, .10$ \\
\hline
\end{tabular}

Note: $* * * p<.001, * * p<.01, * p<.05$. 
Table 5

Correlations Among Focal Variables in Study 2

$\begin{array}{llllll}1 & 2 & 3 & 4 & 5 & 6\end{array}$

\section{Loneliness}

2. Stress

$.53 * * * \quad-$

3. Financial Strain

$.18^{* * *} \quad .15^{* * *} \quad-$

4. Worry

$.18^{* * *} \quad .32 * * * \quad .20 * * *$

5. Depressive Symptoms

$.64 * * *$

$.76^{* * * *}$

$.19 * * *$

$.29 * * *$

6. Sexual Desire

.06

.02

$.09^{* *} \quad .13 * * *$

$-.01$

Note: $* * * p<.001, * * p<.01,{ }^{*} p<.05$. All other variables were assessed at all waves (biweekly) and aggregated across waves. 
Table 6

Main Effects Models with Reports of COVID-related Stressors (Loneliness, Stress, Financial Strain, and Worry) Predicting Sexual Desire for Study 2

\section{Sexual Desire}

\begin{tabular}{lccc|ccc} 
& \multicolumn{3}{c}{ Wave 1 } & \multicolumn{3}{c}{ Overtime } \\
\cline { 2 - 7 } & $\boldsymbol{b}$ & $\boldsymbol{S E}$ & $\boldsymbol{C I}$ & $\boldsymbol{b}$ & $\boldsymbol{S E}$ & $\boldsymbol{C I}$ \\
\hline Loneliness & $.15^{* * *}$ & .03 & $.09, .22$ & $-.15^{* * *}$ & .04 & $-.22,-.08$ \\
Stress & $-.17^{* * *}$ & .04 & $-.24,-.09$ & $-.20 * * *$ & .04 & $-.28,-.12$ \\
Financial Strain & .01 & .03 & $-.05, .07$ & -.05 & .04 & $-.13, .03$ \\
Worry & $.24 * * *$ & .04 & $.16, .32$ & .01 & .05 & $-.08, .11$ \\
\hline
\end{tabular}

Note: $* * * p<.001, * * p<.01, * p<.05$. 


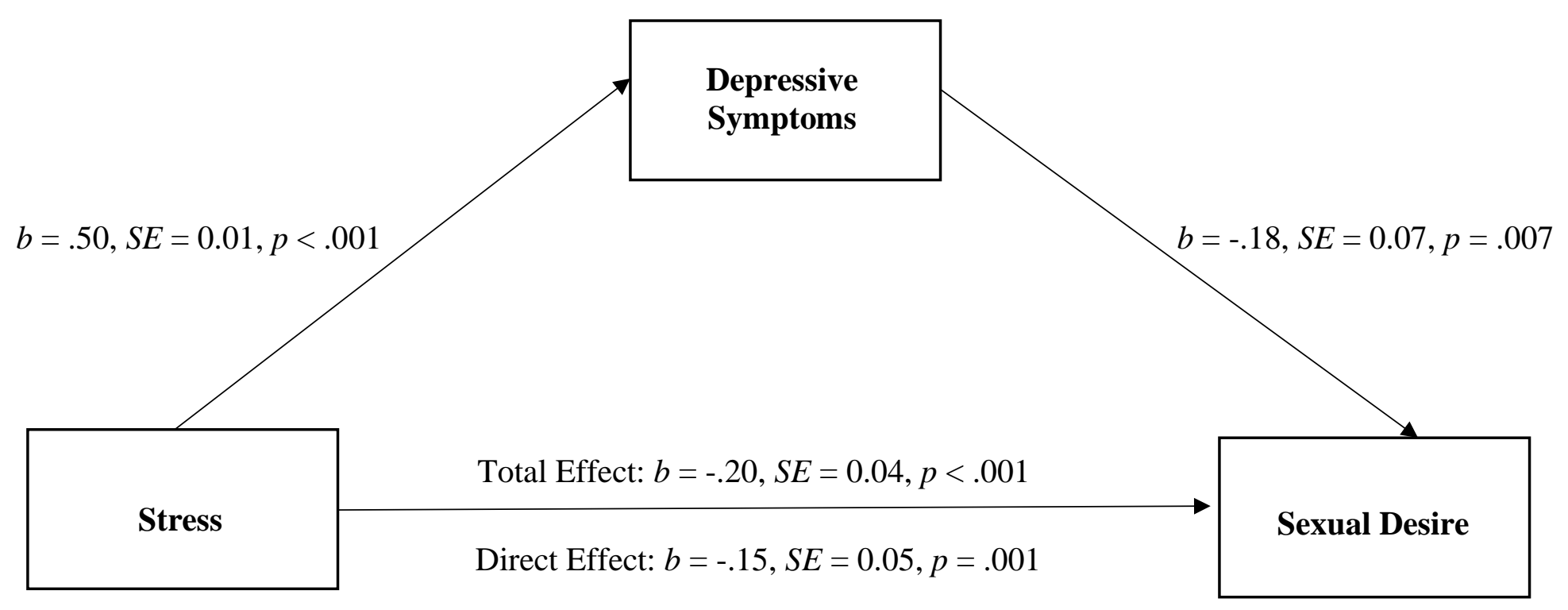

Fig. 1A. People's reports of depressive symptoms as a mediator of the association between people's reports of stress on their sexual desire over the course of the pandemic. 


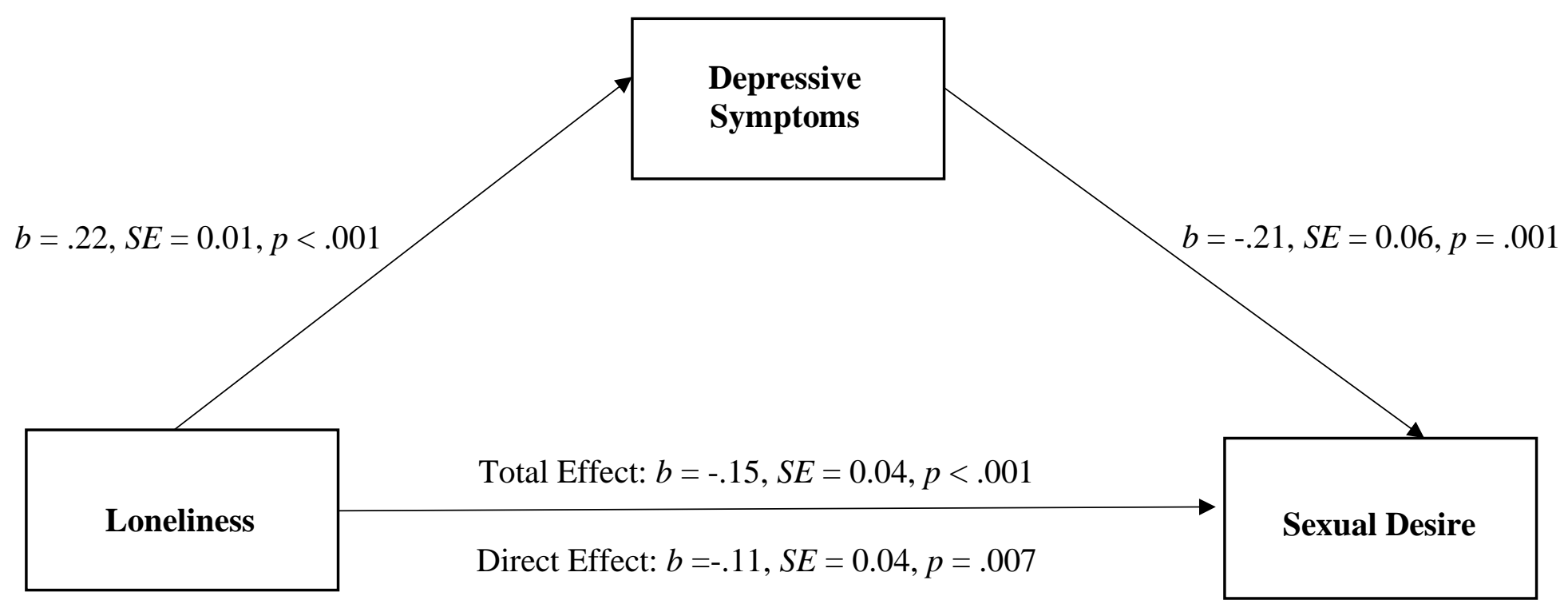

Fig. 1B. People's reports of depressive symptoms as a mediator of the association between people's reports of loneliness on their sexual desire over the course of the pandemic. 


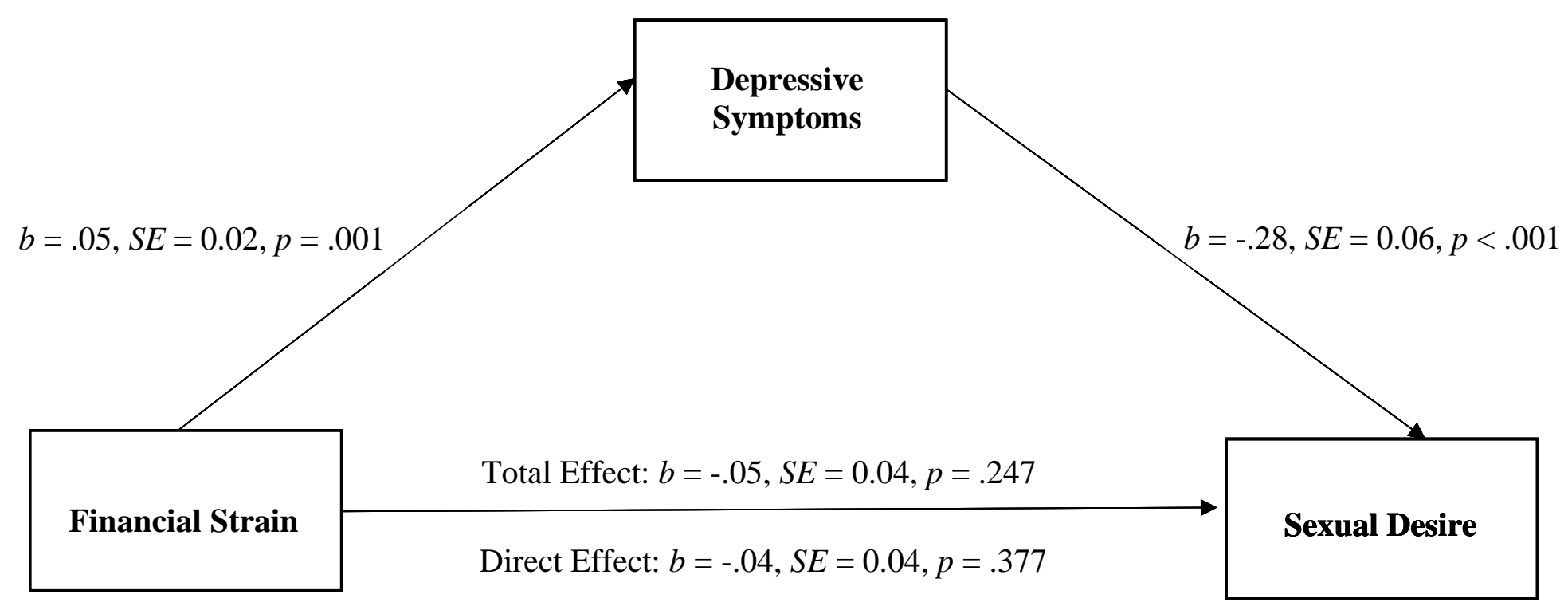

Fig. 1C. People's reports of depressive symptoms as a mediator of the association between people's reports of worry on their sexual desire over the course of the pandemic. 


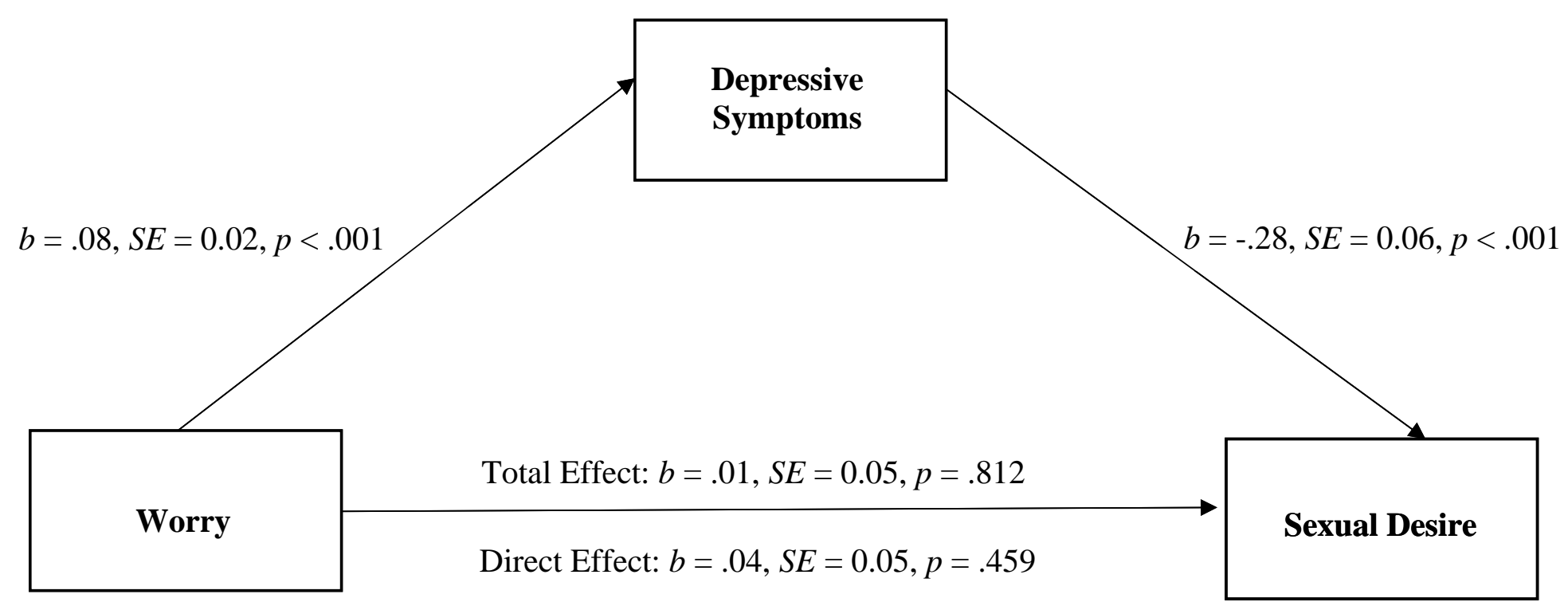

Fig. 1D. People's reports of depressive symptoms as a mediator of the association between people's reports of worry on their sexual desire over the course of the pandemic. 